\title{
The Value of Platelet Indices and platelet to lymphocyte ratio as predictors of severity of Preeclampsia in Iraqi women
}

\author{
Alea Farhan Salman $\quad$ Ban Hadi Hameed $\quad$ Eham Amer Ali \\ The National center of Hematology / University of AL-Mustansiriyah / Baghdad - Iraq \\ AL Yarmouk Teaching Hospital / College of medicine / University of AL-Mustansiriyah / Baghdad - Iraq \\ Department of Chemistry and Biochemistry / College of Medicine / University of AL-Mustansiriyah / Baghdad - Iraq \\ Corresponding author: aleafarhan2@gmail.com \\ Received: 10/Aug. /2021, Accepted: 13 /Sep. /2021
}

\begin{abstract}
To assess the significance of platelet indices and the ratio of platelet to lymphocyte as an early prediction of patients with severity of Preeclampsia. Ninety women were enrolled in three groups: group I: (In=30) women diagnosed as non-severe preeclampsia, group II: $(n=30)$ women diagnosed as severe preeclampsia, and group: III $(n=30)$ age-matched normal pregnant women as a control group. The platelet parameters namely: platelet count (PC), mean platelet volume (MPV), platelet distribution width (PDW), and platelet to lymphocyte ratio (P/L ratio) were evaluated and compared among the study groups.Our findings showed a significant difference among the studied groups regarding the followings: body mass index BMI, systolic blood pressure (SBP) and diastolic blood pressure (DBP) at P-value < 0.05. Mean Platelet Volume and Platelet Distribution Width showed no significant differences between the study groups $(P=0.693$ and 0.118, respectively). In all groups, highly decrease in platelet count $(p=0.01)$ and platelet to lymphocyte ratio $(p=0.024)$ were found. The changes in the platelet indices are more evident in mothers with severe preeclampsia especially the ratio between platelet and lymphocyte. Thus, Platelet indices could be used as biomarkers for early prediction of preeclampsia seriousness.
\end{abstract}

Keywords: Platelet indices, Platelet/Lymphocyte Ratio, Preeclampsia.

\section{Introduction}

Preeclampsia is a multisystem disorder specific to a pregnancy and remains a significant cause of maternal mortality throughout the world (1). It can be characterized by the unusual vascular response to placentation, correlated with increased resistance of systemic vascular. Also, abnormal vascular response associated with enhancement aggregation of platelet, stimulation of the coagulation system, impairment in the function of endothelial cells with decreased perfusion of an organ (2). The criteria for the diagnosis of preeclampsia need de-novo hypertension (BP $\geq 140 / 90 \mathrm{mmHg}$ ) and concentration of proteinuria ( $\geqq 0.3 \mathrm{~g} / \mathrm{d}$ which occurs after 20 weeks of gestation (3).

In a normally state, platelets are inactivated in the bloodstream. But when any damage or activation of endothelial wall comes in contact with platelets, they can be activated (4). In women with risk for preeclampsia $(\mathrm{PE})$, the activation of platelets begins early in gestation, however, during the 3rd trimester of uncomplicated pregnancy the platelets count decreases by an average of $10 \%$ due to hemodilution (5).

Platelet indices are markers for inflammation and/or ischemia. Additionally, as a marker of inflammation and thrombosis, the Platelet/lymphocyte (P/L) ratio is a newly introduced tool that is found to be raised (6). New research indicating that peripheral white blood cell (WBC) counts, such as the platelet-to-lymphocyte $(\mathrm{P} / \mathrm{L})$ ratio, are indicators of a systemic inflammatory response that may provide diagnostic aid and prognostic value for diseases in which inflammation has been accused as an underlying cause of disease progression (7). In preeclampsia, platelet consumption as a result to the abnormal stimulation of coagulation system, lead to the thrombocytopenia. Thrombocytopenia occurs in up to $50 \%$ of women with preeclampsia (8). In the 


\section{Second International Virtual Conference of Biotechnology Research Center (IVCBRC-2021) Journal of Biotechnology Research Center}

Vol.15 No.2

r) 2021

https://doi.org/10.24126/jobrc.2021.15.2.604

P-ISSN: 1815-1140

E-ISSN: 2708-1370

assessment of preeclampsia, these blood indices are good predictive tool with low cost. Though the previous studies showed a good relation between hematological parameters and preeclampsia, but with the severe cases where complications are more

\section{Patients and method}

The current work involved a total of 90 pregnant women at $\mathrm{Al}$ Yarmouk teaching hospital over a period of six months. The participants who were enrolled in this case control study had been assigned from the outpatient clinic and the Obstetric ward for the cases (60 women with preeclampsia) and control group who were attended the antenatal clinic for routine antenatal visit (30 apparently healthy women) who were matched for maternal age and gestational age with cases of preeclampsia. Preeclampsia is diagnosed when the blood pressure equals or more than $140 \mathrm{mmHG}$ for systolic blood pressure and $90 \mathrm{mmHg}$ for diastolic blood pressure on two occasions 6 hours apart with proteinuria ++/ High power field or more in urine. The case group was divided into two subgroups: 30 patients with severe PE when there are features of severe hypertension or end organ damage and 30 patients with non-severe PE when the hypertension and proteinuria were mild to moderate with no end organ affection according to American classification of preeclampsia (10). These patients were allocated to the study after clinical assessment; the blood pressure measurement was done by mercurial sphygmomanometer with the common and early diagnosis is vital, these parameters still need further exploration (9).

Thus, rationale behind this study is to assess the value of these parameters in the diagnosis of preeclampsia and its severity in our clinical setting.

patients in sitting position at rest. The investigations included: complete blood count, renal function test, liver function test, coagulation screen, and urine analysis. All participants gave an informed consent to participate in the study and the protocol of this work had been licensed by the medical council of the college.

Statistical Analysis: The statistical package for social science (SPSS 24) was used for data interpretation which was expressed as means with standard deviations and standard errors of the means. One-Way ANOVA had been applied to analyze the studied variables with significant results applied to $\mathrm{P}$ value less than 0.05 . ROC curve analysis was applied for the $\mathrm{P} / \mathrm{L}$ ratio interpretation to define the diagnostic cutoff criterion.

\section{Results}

The clinical parameters of the studied groups are clarified in table 1, the body mass index, systolic $\mathrm{BP}$ and diastolic BP were significantly different as $P$ values were less than 0.05 . While the maternal age and the gestational age showed a nonsignificant difference.

Table 1: Basic clinical parameters among study groups

\begin{tabular}{|l|c|c|c|c|}
\hline $\begin{array}{l}\text { Variable } \\
(\text { Mean } \pm \text { SD) }\end{array}$ & $\begin{array}{c}\text { Severe } \\
\text { Preeclampsia } \\
\text { N.30 }\end{array}$ & $\begin{array}{c}\text { Non-severe } \\
\text { Preeclampsia } \\
\text { N.30 }\end{array}$ & $\begin{array}{c}\text { Control } \\
\text { N. 30 }\end{array}$ & $\begin{array}{c}\text { P- Values } \\
\text { ANOVA }\end{array}$ \\
\hline Maternal age (years) & $\mathbf{2 9 . 6 3} \pm 6.4$ & $\mathbf{2 7 . 5} \pm 7.6$ & $\mathbf{2 6 . 3 6} \pm 6.5$ & $\mathbf{0 . 0 8 9}$ \\
\hline Gestational age (weeks) & $\mathbf{3 6 . 2 3} \pm 1.6$ & $\mathbf{3 5 . 4 5} \pm 2.1$ & $\mathbf{3 7 . 2 1} \pm 1.4$ & $\mathbf{0 . 6 8}$ \\
\hline $\begin{array}{l}\text { Body mass index } \\
\left(\text { Kg } / \mathbf{m}^{2}\right)\end{array}$ & $\mathbf{4 1 . 2 3} \pm 8.5$ & $\mathbf{3 9 . 4 5} \pm 11.2$ & $\mathbf{3 7 . 6 8} \pm 3.4$ & $\mathbf{0 . 0 0 1 *}$ \\
\hline Systolic BP $(\mathbf{m m H g})$ & $\mathbf{1 6 8} \pm 6.75$ & $\mathbf{1 4 5} \pm 4.89$ & $\mathbf{1 0 0} \pm 8.7$ & $<0.001^{*}$ \\
\hline Diastolic BP $(\mathbf{m m H g})$ & $\mathbf{1 0 6} \pm 8.9$ & $\mathbf{9 2 . 5 6} \pm 8.45$ & $\mathbf{7 6} \pm 7.17$ & $\mathbf{0 . 0 0 4}$ \\
\hline
\end{tabular}

* Refer for significant reading Abbreviations: SD standard deviation, BP: Blood pressure

The platelet indices studied namely MPV, PDW in addition to $\mathrm{P} / \mathrm{L}$ ratio are shown in table 2 which showed a non-significant difference regarding MPV (severe PE $10.34 \pm 0.93$, non-severe PE 10.80 \pm 1.19 , control $10.11 \pm 1.03$ ) fL and PDW (severe PE 14.63 \pm 2.56 , non- severe PE 13.88 \pm 1.88 , control 13.48 \pm 1.99$) \mathrm{fL}$ as $\mathrm{P}$ values were 0.693 and 0.118 consequently. While the $\mathrm{P} / \mathrm{L}$ ratio showed a significant difference among the groups (severe PE 79.28 \pm 43.84 , non- severe PE 106.77 \pm 51.24 , control $112.39 \pm 52.16$ ) as $\mathrm{p}$ value was 0.024 . 


\section{Journal of Biotechnology Research Center}

Vol.15 No.2

P-ISSN: 1815-1140

Published Online: (December) 2021

https://doi.org/10.24126/jobrc.2021.15.2.604

Table 2: Platelet parameters among the study groups

\begin{tabular}{|c|c|c|c|c|c|c|}
\hline Parameter & Groups & Number & Mean & $\begin{array}{l}\text { Standard } \\
\text { Deviation }\end{array}$ & $\begin{array}{l}\text { Standard Error } \\
\text { of Mean }\end{array}$ & $\begin{array}{l}\text { ANOVA } \\
\text { P values }\end{array}$ \\
\hline \multirow{3}{*}{$\begin{array}{l}\text { Platelets } \\
\text { count } / \mathrm{mm}^{3}\end{array}$} & Severe PE & 30 & 180.34 & $\mathbf{5 5 . 0 7}$ & 11.76 & \multirow{3}{*}{ 0.01* } \\
\hline & Non severe PE & 30 & 216.18 & 70.12 & 10.98 & \\
\hline & Control & 30 & 231.21 & 25.65 & 5.4 & \\
\hline \multirow[t]{3}{*}{ MPV (fL) } & Severe PE & 30 & 10.34 & 0.93 & 0.16 & \multirow[t]{3}{*}{0.693} \\
\hline & Non severe PE & 30 & 10.18 & 1.19 & 0.21 & \\
\hline & Control & 30 & 10.11 & 1.03 & 0.18 & \\
\hline \multirow[t]{3}{*}{ PDW (fL) } & Severe PE & 30 & 14.63 & 2.56 & 0.46 & \multirow[t]{3}{*}{0.118} \\
\hline & Non severe PE & 30 & 13.88 & 1.88 & 0.34 & \\
\hline & Control & 30 & 13.48 & 1.99 & 0.36 & \\
\hline \multirow[t]{3}{*}{ P/L Ratio } & Severe PE & 30 & 79.28 & 43.84 & 8.00 & \multirow[t]{3}{*}{ 0.024* } \\
\hline & Non severe PE & 30 & 106.77 & 51.24 & 9.35 & \\
\hline & Control & 30 & 112.39 & 52.16 & 9.52 & \\
\hline
\end{tabular}

* Refer for significant reading

Abbreviations: MPV mean platelet volume, PDW platelet distribution width, P/L platelet / lymphocyte ratio

ROC Curve was applied for $\mathrm{P} / \mathrm{L}$ ratio for preeclampsia versus control as shown in figure 1 and it revealed that a criterion for $\mathrm{P} / \mathrm{L}$ ratio of $\leq$ 82.5 the sensitivity is $43.3 \%$ and specificity is

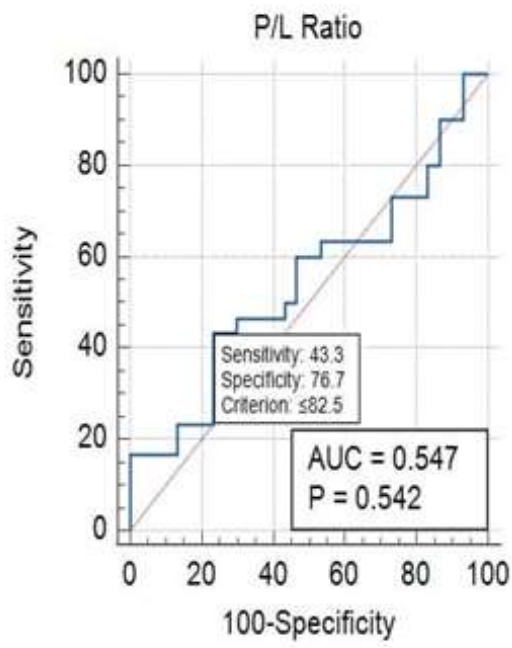

Figure 1: ROC Curve for preeclampsia versus control. non severe cases.

ROC Curve was applied for $\mathrm{P} / \mathrm{L}$ ratio for severe preeclampsia versus non severe cases as shown in figure 2 and it revealed that a criterion for $\mathrm{P} / \mathrm{L}$ ratio of $>33$ the sensitivity is $100 \%$ and specificity is
$76.7 \%$ with area under the curve 0.55 and $95 \%$ Confidence interval 0.41 to 0.68 with a significance level 0.54 .

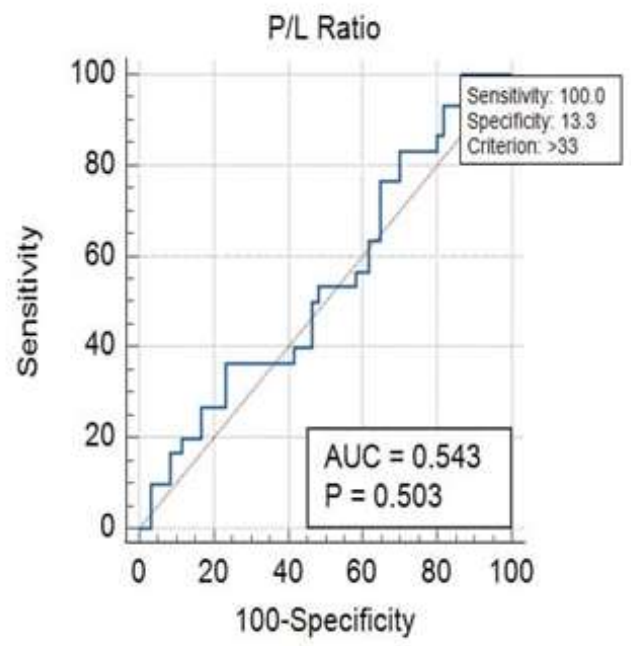

Figure 2: ROC Curve for severe preeclampsia versus

$13.3 \%$ with area under the curve 0.54 and $95 \%$ Confidence interval 0.43 to 0.65 with a significance level 0.50 . 


\section{Second International Virtual Conference of Biotechnology Research Center (IVCBRC-2021) Journal of Biotechnology Research Center}

Vol.15 No.2

\section{Discussion}

Preeclampsia is a significant cause of maternal and fetal morbidity and mortality because it is associated with an increased risk of preterm birth, Intrauterine growth restriction, placental abruption $(8,9)$. Pregnancy is associated with complex and not fully understood changes that involve blood clotting. Information regarding platelet behavior in normal pregnancy has shown mixed results. PLT indices are a set of indicators that are used to measure the number of PLT and PLT morphology (11). Hence in the present study, an attempt was made to understand the relationship between the platelet count, MPV, PDW, and P/L ratio with preeclampsia and tried to evaluate whether these parameters could be used as markers in the early diagnosis of preeclampsia.

Preeclampsia can be non-severe and severe. Severe preeclampsia is characterized by more substantial blood pressure elevations (systolic $\geq 160 \mathrm{~mm} \mathrm{Hg}$, diastolic $\geq 110 \mathrm{~mm} \mathrm{Hg}$ ), a greater degree of proteinuria ( $>5 \mathrm{~g} / 24$ hours), and the presence of symptoms associated with target organ involvement (12).

High BMI, especially obesity, increase the risk of preeclampsia as extensively documented in multiple studies (13). In this study, we show that by using BMI as a continuum, we find in both cases (severe and non-severe) that increased BMI in pregnant women compered to healthy pregnant women. Obesity has been shown to represent a definite risk for the development of preeclampsia during pregnancy (14). Obese patients present a metabolic syndrome (MS) characterized by insulin resistance with an excessive flux of fatty acids and a proinflammatory state that contribute to disrupting the equilibrium between immunology, metabolic alterations, and systemic inflammation that are necessary for a healthy pregnancy (15) .

In our study, the mean age of study subjects was $27.5 \pm 7.6$ and $29.63 \pm 6.4$ years old in the non-severe preeclampsia and severe preeclampsia group. These findings were comparable to previous reports published by various researchers in the literature. Prakash et al. reported mean age of $28.7 \pm 3.4$ years; however, a study done by Onishi et al. observed a similar mean age compared to the present study $(16,17)$. In the present study, most mothers, i.e., $55.6 \%$ and $57.1 \%$, were in the gestational age of 35 and 36 weeks in non-severe and severe preeclampsia groups respectively.

PLT count in this study showed a significant decrease in patients with $\mathrm{PE}$ compared to the control group $(180 \pm 55.07 \mathrm{UL})$ for severe, $(216 \pm$ $70.12 \mathrm{UL})$ for non-severe, and (231.21 $\pm 25.65 \mathrm{UL})$ for the control group with $(\mathrm{P}=0.01)$. This was consistent with a study have been done by Gupta et al. that found a significant decrease in PLT count in PE patients compared to the control group (18). Additionally, Sameer et al. observed that the PLT count was significantly lower in PE. The lower platelet count in preeclampsia is associated with abnormal activation of the coagulation system and is believed to reflect increased platelet consumption. (19).

In the current study, there was a non-significant difference in MPV and PDW from normotensive pregnant women, which is the result of an agreement with Cyehan et al. (20) found no significant difference in MPV between preeclampsia and the normal pregnant group and also, Altibas et al. reported that MPV is not a significant predictor of the severity of preeclampsia (21). However, Gogoi et al reported non-statistically significant difference in PDW between PE patients and controls (22).

In this study focuses on inflammatory markers i.e. the $\mathrm{P} / \mathrm{L}$ ratio which showed a significant difference between the study groups as it was significantly decreased in women with $\mathrm{PE}$ compared to the control group. This result is in agreement with previous studies such as Toptal and colleagues who found a lower $\mathrm{P} / \mathrm{L}$ ratio in $\mathrm{PE}$ versus normal pregnancies and those with severe $\mathrm{PE}$ comparing with non-severe PE which is an agreement with our study (23). In subgroup analysis, Yucel and Ustun found that $\mathrm{P} / \mathrm{L}$ ratio was decreased significantly in the patients with severe PE than in the healthy pregnant women, these results matched our results (24). Karpas and colleagues conducted a study of consecutive pregnant women with PE (non-severe, severe disease) and healthy pregnant women. They found decreased $\mathrm{P} / \mathrm{L}$ ratio in the non-severe PE group 


\section{Second International Virtual Conference of Biotechnology Research Center (IVCBRC-2021) Journal of Biotechnology Research Center}

Vol.15 No.2

2021 hips/ldoi.org/10.24126/.0bre.2021.15.2.604

P-ISSN: 1815-1140

Published Online: (December) 2021

https://doi.org/10.24126/jobrc.2021.15.2.604

E-ISSN: 2708-1370

compared with the control group, However, P/L ratio was increased in the severe PE group compared with the non-severe PE group and healthy pregnant controls (25). Hemostasis and coagulation abnormalities (possibly due to endothelial damage), including enhanced platelet activity, have been implicated in the pathogenesis of pre-eclampsia (26). Some research reports have indicated that increased $\mathrm{P} / \mathrm{L}$ ratio is a sensitive marker of inflammation and a prognostic marker in breast cancer, ovarian cancer, and colorectal cancer $(27,28)$. P/L ratio has been studied in a large number of epidemiological studies as indicators of systemic inflammation, and lymphocytes are known to play an important role in the overall inflammatory response, reducing number of lymphocytes induced by programmed cell death may increase inflammatory damage. $\mathrm{P} / \mathrm{L}$ ratio has been reported to reflect hyperactive inflammatory pathways (29). MPV, PCT, and PDW indices are known parameters that reflect platelet activation and modification in the blood hemostatic system, including endothelial cell damage $(30,31)$. One study showed disagreement with our findings, that of Yavuzcan et al (30).

\section{Conclusion}

This study showed that platelet count and P/L ratio decrease while MPV and PDW increase as pregnancy progresses, and these changes are more prominent in severe preeclampsia than in non-

\section{References}

1. Alisi PN, Buseri FI, Alisi CS. Some blood cell changes and alteration in renal and hepatic function in preeclampsia: a study in Owerri Nigeria. Int Blood Res Rev. 2014 Available from: Accessed on December 30, (2020).

2. Alkholyå EAM, Faragc EA, Beheryñ MA, Ibrahimå MM. The significance of platelet count, mean platelet volume and platelet width distribution in preeclampsia. AAMJ. (2013); 11: 200-214.
ROC analysis was performed to determine diagnostic $\mathrm{P} / \mathrm{L}$ ratio values for preeclampsia. In this study, P/L ratio cut-off value at $\leq 82.5$ showed sensitivity $43.3 \%$ with higher specificity $76.7 \%$ to differentiate preeclampsia from control whereas the cut off value $>33$ showed excellent sensitivity $100 \%$ but low low specificity $13.3 \%$ to differentiate severe from non-severe cases. Another study showed the $\mathrm{P} / \mathrm{L}$ ratio can differentiate normotensive pregnant women from preeclamptic pregnant women at a cut-off value of 80.70 with a sensitivity of $81.1 \%$ and specificity of $95.1 \%$. The cut of value reported by Gezer et al. was 126.8 or higher, with the sensitivity and specificity of $71.8 \%$ and $72.4 \%$ respectively to predict preeclampsia (32). Kholief and his co-workers reported a cut-off value less than or equal to 77.5 for $\mathrm{P} / \mathrm{L}$ ratio with $35.71 \%$ sensitivity, $85.71 \%$ specificity (33). In this study, the AUC for P/L ratio showed a statistically nonsignificant differences, this is in agreement with Yucel and Ustun who reported that the AUC for $\mathrm{P} / \mathrm{L}$ ratio was not statistically significant $(\mathrm{p}=0.104)$ (24).

severe preeclampsia. It was also found that there is an association between the $\mathrm{P} / \mathrm{L}$ ratio and the severity of preeclampsia, and thus the $\mathrm{P} / \mathrm{L}$ ratio can be used as a parameter in the diagnosis and prediction of severe preeclampsia.

3. Rebarber A .Hypertensive disorders of pregnancy. Evidence-2. based ObstetGynecol. (2019): 255-264.

4. Holthe MR, Staff AC, Berge LN, Lyberg T. Different levels of platelet activation in preeclamptic, normotensive pregnant, and nonpregnant women. Am J ObstetGynecol. (2004); 190: 1128-1134.

5. McCrae KR. Thrombocytopenia in pregnancy. Hematology 2010, the American Society of Hematology Education Program Book. (2010): 397-402. 
) 2021

P-ISSN: 1815-1140

Published Online: (December) 2021

https://doi.org/10.24126/jobrc.2021.15.2.604

E-ISSN: 2708-1370

6. Çakıroğlu Y, Vural F, Vural B. The inflammatory markers in polycystic ovary syndrome: association with obesity and IVF outcomes. J Endocrinol Invest. (2016); 39(08): 899-907.

7. Kirbas A, Biberoglu E, Daglar K, İskender C, Erkaya S, Dede H, et al. Neutrophil-to-lymphocyte ratio as a diagnostic marker of intrahepatic cholestasis of pregnancy. Eur J Obstet Gynecol Reprod Biol. (2014); 180: 12-15.

8. Pishko AM, Levine LD, Cines DB. Thrombocytopenia in 7. pregnancy: Diagnosis and approach to management. Blood Rev. (2019): 100638 .

9. Sachan, et al.: Hematological Indices, MPV, RDW and platelet counts predictor of preeclampsia. Journal of Family Medicine and Primary Care, Volume 10: Issue 2: February 2021.

10. American College of Obstetricians and Gynecologists: Hypertension in pregnancy Report of the American College of Obstetricians and Gynecologists Task Force on Hypertension in pregnancy. Obstet Gynecol 122:1122. 2013b.

11. Juan $P$, Stefano $G$, Antonella $S$, Albana $C$. Platelets in pregnancy. JPrenatal Med. (2011); 5: 90.

12. Machado S, Figueiredo N, Borges A, Pais MS, Freitas L, Moura P, et al. Acute kidney injury in pregnancy: a clinical challenge. J Nephrol. (2012); 25(01): 19-30.

13. Poorolajal J, Jenabi E. The association between body mass index and preeclampsia: a metaanalysis. J Matern Fetal Neonatal Med. (2016) Nov; 29(22): 3670-3676.

14. Mbah AK, Kornosky JL, Kristensen S, et al. Super-obesity and risk for early and late preeclampsia. BJOG. (2010); 117(8): 997-1004.
15. Grieger JA, Bianco-Miotto T, Grzeskowiak LE, Leemaqz SY, Poston L, McCowan LM et $a l$,Metabolic syndrome in pregnancy and risk for adverse pregnancy outcomes: A prospective cohort of nulliparous women. PLoS Med. (2018); 15(12): e1002710.

16. Missfelder-Lobos H, Teran E, Lees C. Platelet changes and subsequent development of preeclampsia and fetal growth restriction in women with abnormal uterine artery doppler screening. Ultrasound Obstet Gynecol. (2002); 19: 443-448.

17. Monteiro G, Subbalakshmi NK, Pai SR. Relevance of measurement of hematological parameters in subjects with pregnancy induced hypertension. Nitte Univ J Health Sci. (2014); 4(1): 15-205.

18. Gupta A, Gaur BS, Mishra KB, Dubey I. A comparison of platelet count in severe preeclampsia, mild preeclampsia and normal pregnancy. Int J Res Med Sci. (2018); 6: 671-675.

19. Sameer MA, Meshram DP, Deshpande SA, Sadhu D, Pandit S. Role of platelet count as important prognostic marker in pregnancy induced hypertension. J Dent Med Sci (IOSR-JDMS). (2014); 13: 39-43.

20. Altibas $S$, Togrul $C$, Orhan $A$, Yucel $M$, Danisman N. Increased MPV is not a significant predictor of preecalmpsia during pregnancy. $\mathrm{J}$ clin Lab Anal. (2012); 26: 403-406.

21. Santos EV, Filho JM. Measurement of platelet parameters in normal and preeclamptic pregnant women, Rev. Bras. Ginecol. Obstet. (2004); (26), (n. 3): 201-206.

22. Gogoi P, Sinha P, Gupta B, Firmal P, Rajaram S. Neutrophil-to-lymphocyte ratio and platelet indices in pre-eclampsia. Int $J$ Gynaecol Obstet. (2019); 144: 16-20. 
23. Toptas M, Asik H, Kalyoncuoglu M, Can E, Can MM. Are neutrophil/ lymphocyte ratio and platelet/lymphocyte ratio predictors for severity of preeclampsia. J Clin Gynecol Obstet. (2016); 5: 2731.

24. Yucel B, Ustun B. Neutrophil to lymphocyte ratio, platelet to lymphocyte ratio, mean platelet volume, red cell distribution width and plateletcrit in preeclampsia. Pregnancy Hypertens. (2017); 7: 29-32.

25. Kirbas A, Ersoy AO, Daglar K, Dikici T, Biberoglu EH, Kirbas O, et al. Prediction of preeclampsia by first trimester combined test and simple complete blood count parameters. J Clin Diagn Res. (2015); 9:QC20-Q C23.

26. Cakmak B, Gulucu S, Aliyev N, Ozsoy Z, Nacar M, Koseoglu D. Neutrophil lymphocyte and plateletlymphocyte ratios in endometrial hyperplasia. Obstet Gynecol Sci. (2015); 58(2): 157-161.

27. Turkmen K, Erdur FM, Ozcicek F, Ozcicek A, Akbas EM, Ozbicer A, et al. Platelet-to-lymphocyte ratio better predicts inflammation than neutrophiltolymphocyte ratio in end-stage renal disease patients. Hemodial Int (2013); 17(3): 391396.

28. An X, Ding PR, Li YH, Wang FH, Shi YX, Whang ZQ, et al. Elevated neutrophil to lymphocyte ratio predicts survival in advanced pancreatic cancer. Biomarkers. (2010); 15(6): 516522.

29. Yang SW, Cho SH, Kwon HS, Sohn IS, Hwang HS. Significance of the platelet distribution width as a severity marker for the development of preeclampsia. Eur J Obstet Gynecol Reprod Biol. (2014); 175: 107-111.

30. Yavuzcan A, Caglar M, Ustun Y, Dilbaz S, Ozdemir I, Yildiz E, et al. Mean platelet volume, neutrophillymphocyte ratio and platelet-lymphocyte ratioin severe preeclampsia. Ginekol Pol. (2014); 85(3):197-203.

31. Dundar $\mathrm{O}$, Yoruk $\mathrm{P}$, Tutuncu $\mathrm{L}$, et al. Longitudinal study of platelet size changes in gestation and predictive power of elevated MPV in development of preeclampsia. Prenat Diagn. (2008); 28:1052-1056.

32. Gezer C, Ekin A, Ertas IE, Ozeren M, Solmaz $\mathrm{U}$, Mat $\mathrm{E}$, Taner CE. High first-trimester neutrophil-tolymphocyte and platelet-tolymphocyte ratios are indicators for early diagnosis of preeclampsia. Ginekologia Polska. (2016); 87(6): 431-435.

33. Kholief A, Swilam R, Elhabashy A, Elsherief R. Neutrophil/ lymphocyte ratio, platelet/lymphocyte ratio, and c-reactive protein as markers for severity of pre-eclampsia. Research and Opinion in Anesthesia and Intensive Care. (2019); 6(1): 1-8. 


\section{Journal of Biotechnology Research Center}

Vol.15 No.2

P-ISSN: 1815-1140

Published Online: (December) 2021 https://doi.org/10.24126/jobrc.2021.15.2.604

E-ISSN: 2708-1370

قيمة مؤشرات الصفائح الدموية ونسبة الصفائح الدموية إلى الخلايا الليمفاوية كمؤشرات لشدة مقدمة الارتعاج لاى

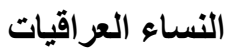

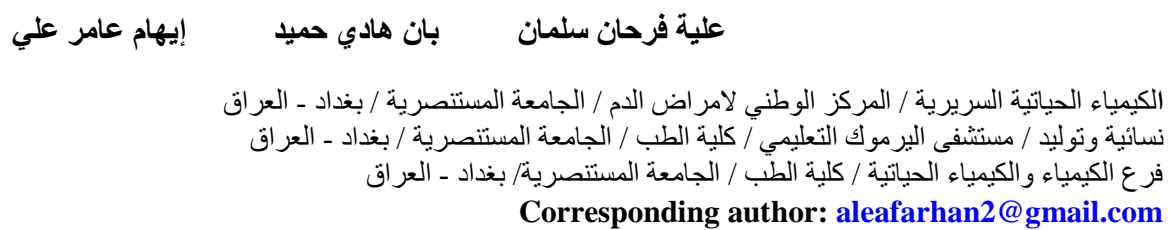

الخلاصة

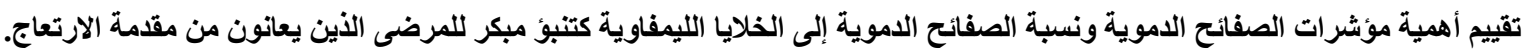

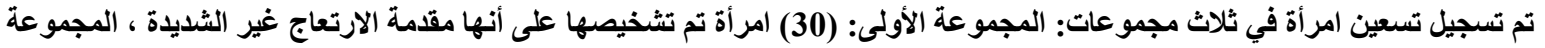

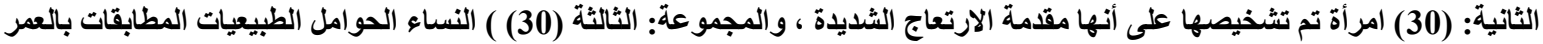

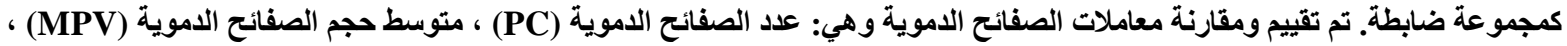

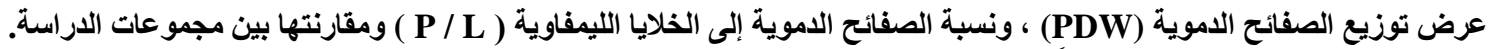

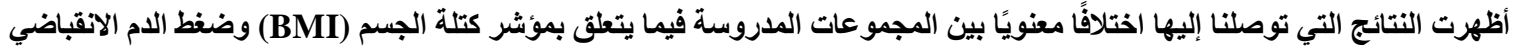

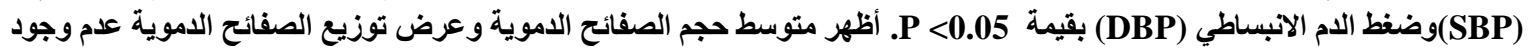

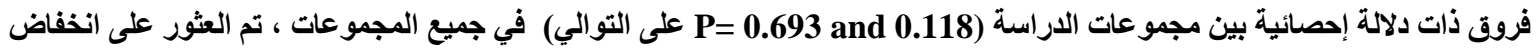

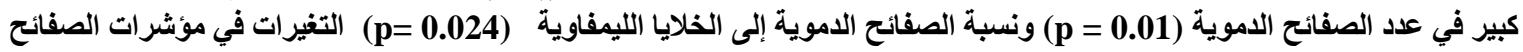

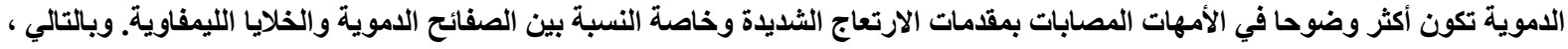
يمكن استخدام مؤشرات الصفائح الاموية كمؤشرات حيوية للتنبؤ المبكر بخطورة مقدمة الارتعاج. الكلمات المفتاحية: مؤشرات الصفائح الدموية ، نسبة الصفائح الاموية / الذلايا الليمفاوية ، مقدمة الارتعاج. 